\title{
Effect of phase separation on crystallization of glasses in the $\mathrm{BaO}-\mathrm{TiO}_{2}-\mathrm{SiO}_{2}$ system
}

\author{
Hiroyuki HIJIYA, Tetsuo KISHI and Atsuo YASUMORI ${ }^{\dagger}$ \\ Department of Materials Science and Technology, Tokyo University of Science, 2641, Yamazaki, Nodashi, Chiba, 278-8510
}

\begin{abstract}
The effects of phase separation on the crystallization behavior of glasses were investigated in order to materialize a highluminous glass-ceramic phosphor, which consists of fine phosphor crystals and a transparent glass matrix prepared due to phase separation. The glass ceramics in $\mathrm{BaO}_{-} \mathrm{TiO}_{2}-\mathrm{SiO}_{2}$ has the potential to show high photoluminescence intensity, because of multiple light scattering at the boundary between the phosphor crystal and the glass matrix. The crystallization behaviors of the glasses were examined using both the XRD analyses for an isothermal heat treatment process and the DTA measurements as a non-isothermal treatment process. The phase-separation in the glass significantly affected the subsequent crystallization behavior. In the non-phase-separated glasses, surface crystallization occurred first, and crystallization then proceeded inside the glasses. In the phase-separated glasses, the crystallization was considered to start at the boundary of two glass phases inside the glass and the crystals grew in $\mathrm{BaO}_{-} \mathrm{TiO}_{2}$-rich phases. This apparent bulk crystallization owing to the phase separation has the potential to materialize a high-performance phosphor composite.
\end{abstract}

(C)2009 The Ceramic Society of Japan. All rights reserved.

Key-words : Phase separation, Kissinger equation, Fresnoite

[Received July 16, 2008; Accepted October 16, 2008]

\section{Introduction}

A large number of studies have investigated inorganic phosphor materials because they have gained considerable attention as essential elements in various light emitting and display devices. In order to prepare high-performance phosphor materials, it is necessary to consider not only the light emission efficiency of a phosphor, but also various effects, such as the reflection and the scattering of excited and emitted light on the phosphor surface, as well as the particle size and the shape morphology of the phosphor crystals.

In contrast, phase-separated glasses such as sodium borosilicate glasses have been widely applied to various commercial functional glasses, which have high chemical and thermal durability and porous characteristics owing to their micro-nanoscaled fine phase separation structure. There have been few reports on phase-separated glasses as a host material for the emission center of fine phosphors, because the boundary of two glass phases owing to fine phase separation structure acts as an origin of light scattering and causes deterioration in the emission property due to low transmittance, as compared with a homogeneous glass. However, since Lawandy and Balachandran reported that an emission enhancement from laser dye supported on nano particles dispersed in a liquid medium owing to their multiple light scattering, ${ }^{1)}$ the fluorescence characteristics of the various phase-separated glasses have been studied in the $\mathrm{Na}_{2} \mathrm{O}-\mathrm{B}_{2} \mathrm{O}_{3}-\mathrm{SiO}_{2}$ : $\mathrm{Eu}$ system, ${ }^{2)}$ and the glass ceramics in $\mathrm{Y}_{2} \mathrm{O}_{3}-\mathrm{Al}_{2} \mathrm{O}_{3}-\mathrm{SiO}_{2}: \mathrm{Eu},{ }^{3)} \mathrm{CaO}-\mathrm{Al}_{2} \mathrm{O}_{3}-\mathrm{SiO}_{2}: \mathrm{Eu},{ }^{4)}$ and $\mathrm{ZnO}-\mathrm{SiO}_{2}$ : $\mathrm{Mn}^{2+}{ }^{2)}$ systems, for example. For these glass ceramics, which contain rare earth or transition metal ions as emission centers, we reported that a combination of a phase separation and a subsequent crystallization was very effective for enhancing fluorescent

Corresponding author: A. Yasumori; E-mail: yasumori@rs.noda. tus.ac.jp property. We have also reported that the fluorescence properties of glass ceramic prepared from the melt-quenched glasses in the $\mathrm{BaO}-\mathrm{TiO}_{2}-\mathrm{SiO}_{2}$ system, which has a large immiscibility region. ${ }^{6}$ Their emission centers were not ions, but the crystal, fresnoite $\left(\mathrm{Ba}_{2} \mathrm{TiSi}_{2} \mathrm{O}_{8}\right)$, precipitated in the initial glass and the emission intensity of this glass ceramics was enhanced when the phase separation occurred in the initial glass. As the origin of this emission enhancement, we must consider not only the effect of the light scattering caused by the boundary between fresnoite crystals and the glass matrix but also the effect of the initially formed phase separation in the glass on the crystallization behavior of fresnoite. Although surface crystallization has a disadvantage in that most of the incident excitation light is reflected on the surface of glass ceramics, the bulk crystallization and resulting microstructure, which consists of fresnoite crystals and $\mathrm{SiO}_{2}-$ rich glassy phase, are very effective for improvement of PL intensity because of the penetration of the incident light and subsequent internal light scattering. Therefore, it is extremely important to investigate the crystallization behavior of glass ceramic phosphor in order to optimize its internal microstructure.

The dominant crystallization mechanism for glass materials is normally a nucleation-growth mechanism. Thus, a glass composition and some nucleation agent added to a glass strongly affect the crystallization behavior. The nucleation-growth mechanism for glass crystallization is often analyzed using the JohnsonMehl-Avrami (JMA) theory. ${ }^{7)-9)}$ This theory has been applied to the analysis of various glass systems without phase separation, such as $\mathrm{Li}_{2} \mathrm{O}-\mathrm{SiO}_{2},{ }^{10), 11)}$ and $\mathrm{CaO}-\mathrm{GaO}_{2}-\mathrm{SiO}_{2}{ }^{12)}$ On the other hand, there are two types of glass crystallization processes, one is bulk crystallization and another is surface crystallization. These crystallization behaviors are normally dominated by glass component species, their composition, and the size of glass material. The crystallization mechanisms have been reported for some phase-separated glass systems, such as $\mathrm{Al}_{2} \mathrm{O}_{3}-\mathrm{SiO}_{2}{ }^{13)}$ and $\mathrm{Li}_{2} \mathrm{O}-$ $\mathrm{SiO}_{2},{ }^{14), 15)}$ and the main process of crystallization was considered 
to be very similar to the bulk process but was independent of composition. In the composition of the $\mathrm{BaO}-\mathrm{TiO}_{2}-\mathrm{SiO}_{2}$ system, which was out of its immiscibility region, it was reported that the crystallization process of the glass in stoichiometric composition of fresnoite $\left(40 \mathrm{BaO} \cdot 20 \mathrm{TiO}_{2} \cdot 40 \mathrm{SiO}_{2} \mathrm{~mol} \%\right)$ was bulk crystallization and the glasses of other compositions showed surface crystallization. ${ }^{16), 17)}$ The activation energies of the crystallization for the glasses in some compositions of this system were also evaluated. ${ }^{18)-20)}$

In the present study, the effect of phase separation on the crystallization behavior of the glasses in the $\mathrm{BaO}-\mathrm{TiO}_{2}-\mathrm{SiO}_{2}$ system was investigated from the isothermal and non-isothermal treatments on the as-quenched glasses. The crystallization behavior of the isothermal heat-treated glasses was examined by X-ray diffraction (XRD) analysis, and the non-isothermal heat-treated glasses were analyzed using a differential thermal analysis (DTA) and the JMA theory described below.

\section{Theoretical considerations}

Glass crystallization can generally be divided into two processes: nucleation and crystal growth. In this case, the JohnsonMehl-Avrami (JMA) equation can explain the thermodynamics of a phase transition on a nucleation and a crystal growth under an isothermal treatment. ${ }^{7-9)}$ In contrast, there are analyses, such as DTA analysis, that can be applied to the crystallization behavior in non-isothermal treatment. For analysis in the non-isothermal treatment, the Kissinger equation, which is derived from the JMA theory, ${ }^{21)}$ is applied. The Kissinger equation is given as follows:

$$
\ln \left(\alpha / T_{\mathrm{p}}^{2}\right)=-\left(E / R T_{\mathrm{p}}\right)+\text { const. }
$$

where $T_{\mathrm{p}}$ is the temperature of the maximum DTA crystallization peak, $\alpha$ is the heating rate, and $R$ is the universal gas constant. The activation energy $E$ can be evaluated from the plot of $\ln \left(\alpha / T_{\mathrm{p}}^{2}\right)$ with respect to $1 / T_{\mathrm{p}}$.

In the present study, we examined the crystallization behavior, in particular the change in the activation energy, using powder samples of different particle sizes. In this case, the effect of the nucleation on the surface of the particles should be taken into consideration. Matsusita and Sakka suggested that the Kissinger equation can be applied to the analysis of the crystallization when the nuclei number is constant during the crystallization process. ${ }^{19), 20)}$ Since the evaluated activation energy shows a much lower value than the actual value when the nucleation and the crystal growth proceed at the same time, they proposed the modified Kissinger equation, as follows:

$$
\ln \left(\alpha^{n} / T_{\mathrm{p}}^{2}\right)=-\left(m E / R T_{\mathrm{p}}\right)+\text { const. }
$$

where $n$ is a constant defined as an Avrami parameter and $m$ represents the dimension of crystal growth. The relation between these two factors is given as $m=n-a$, where $a$ is a nucleation parameter. When the number of nuclei is constant throughout the growth of nuclei and crystal, $a=0$, or $m$ is equal to $n$. If the number of nuclei increases during crystallization, $a$ is positive ( $a$ $>0$ ). In this case, $a$ and the resultant $m$ change with the heating rate during the crystallization process. In previous studies, Ranganthan and Von Heimendahk ${ }^{22}$ and Matusita and Komatsu $^{23)}$ reported defined the $m$ and $n$ values as $n=1$ and $m=1$ for the surface crystallization mechanism and $n=4$ and $m=3$ for the bulk crystallization mechanism.

\section{Experimental}

The compositions of the glasses prepared in the present study were $(40-2 x / 3) \mathrm{BaO}-(20-x / 3) \mathrm{TiO}_{2}-(40+x) \mathrm{SiO}_{2} \mathrm{~mol} \%(x=9$, 18,21 , and 27), in which $x=0$ corresponds to the composition of fresnoite $\left(\mathrm{Ba}_{2} \mathrm{TiSi}_{2} \mathrm{O}_{8}\right), x=9$ and 18 are outside the estimated immiscibility region in this ternary system, and $x=21$ and 27 are inside the immiscibility region. ${ }^{6)}$ Reagent-grade raw materials of $\mathrm{BaCO}_{3}$ (High Purity Chemicals, 99.5\%), $\mathrm{TiO}_{2}$ (Wako Pure Chemical Ind., 98.5\%), and $\mathrm{SiO}_{2}$ gel (Wako Pure Chemical Ind.) were weighed and mixed in a glass mortar. The glass batch was melted in an alumina crucible at $1500-1650^{\circ} \mathrm{C}$ for one $\mathrm{h}$ and was then quenched. The melt-quenched samples were 2mm-thick and had optical-grade polished surfaces that were heat-treated at $1000^{\circ} \mathrm{C}$ for two $\mathrm{h}$ in air. The XRD patterns of the crystallized samples were measured by XRD (Shimadzu Co., XRD-6100) as their surfaces were successively polished until a designated thickness was reached. The degree of orientation of the precipitated crystals was evaluated based on the change of the obtained XRD patterns in the depth direction.

The DTA was carried out for powder samples of meltquenched glasses using a DTA apparatus (Shimadzu Co., DTA50) in air in order to determine their crystallization behaviors under the non-isothermal heat treatment. Ground glasses of four granular sizes, which were 32-45 $\mu \mathrm{m}, 75-150 \mu \mathrm{m}, 300-600 \mu \mathrm{m}$, and $600-750 \mu \mathrm{m}$, were supplied to the DTA measurements. These granular samples were prepared using a sieving technique. The heating rates in the DTA measurement were $5,10,15$, and $20 \mathrm{~K} / \mathrm{min}$ for the respective samples.

The phase separation textures in the melt-quenched glasses and the crystallization conditions of the heat-treated glasses were observed using a scanning electron microscope (SEM; JEOL, JSM-5800).

\section{Results and discussion}

\subsection{Crystallization behavior under isothermal heat treatment}

In this examination, we selected two compositions, $x=9$ and 27 , as the non-phase-separated and phase-separated glasses, respectively. The XRD patterns of the surfaces of the samples and inside the samples are shown in Fig. 1(a-1) for $x=9$ and Fig. (b) for $x=27$, and the particular range of the patterns from $2 \theta$ $=20^{\circ}$ to $30^{\circ}$ of $x=9$ are also shown in Fig. 1(a-2). In the sample of $x=9$, the diffraction peaks from the crystal planes perpendicular to the $c$-axis of fresnoite, such as (001), (002), (003), and (004), were only observed at the initial surface of the heat-treated sample and inside the sample. This indicates that the precipitated fresnoite in the glass oriented to the direction of the $c$-axis, which was similar to the results reported by Takahashi et al. ${ }^{16)}$ The intensity of the diffraction peak from (001) at the surface was lower than that of the inside, and the peak from (211) decreased in the depth direction. These results indicate that the degree of the $c$-axis orientation was small at the surface of the sample but became large just beneath the surface. In contrast, the sample of $x=27$ showed a slight $c$-axis orientation at the surface, considering the relatively large diffraction peak from (002) but did not show any orientation inside the sample.

The fresnoite crystal has a cubic crystal structure and the diffraction peak from the (211) plane is a maximum peak. Thus, the degree of the $c$-axis orientation index $(O I)$ was defined as the ratio between the integrated diffraction peak intensities, $I_{211}$ and $I_{002}$ from the (211) and (002) planes given by the following equation: ${ }^{19)}$ 


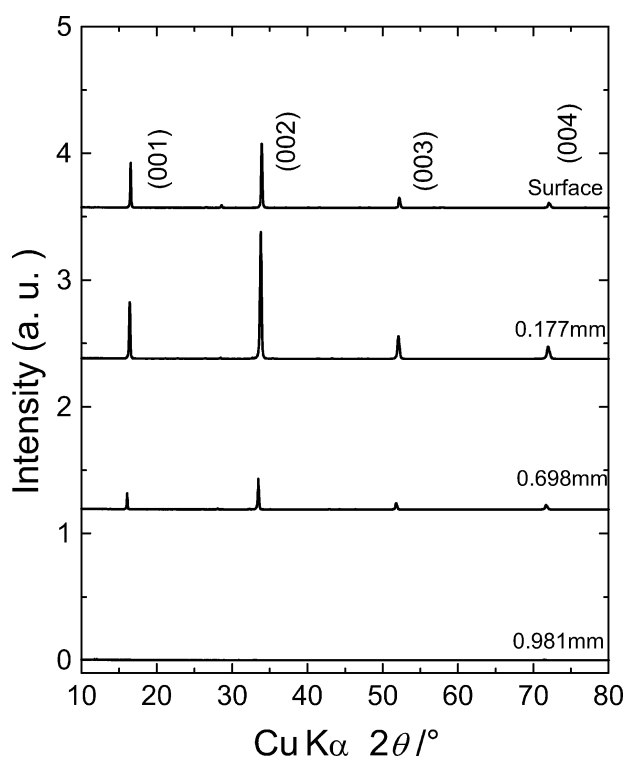

(a-1)

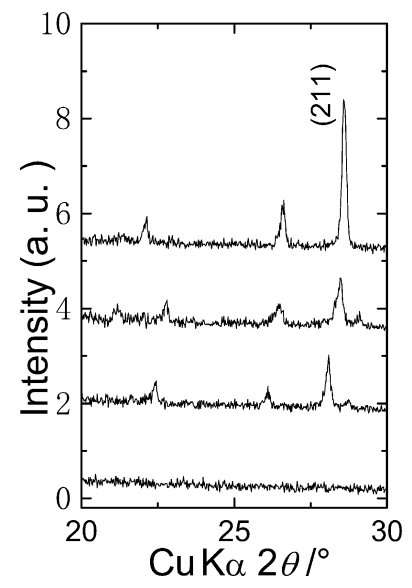

(a-2)

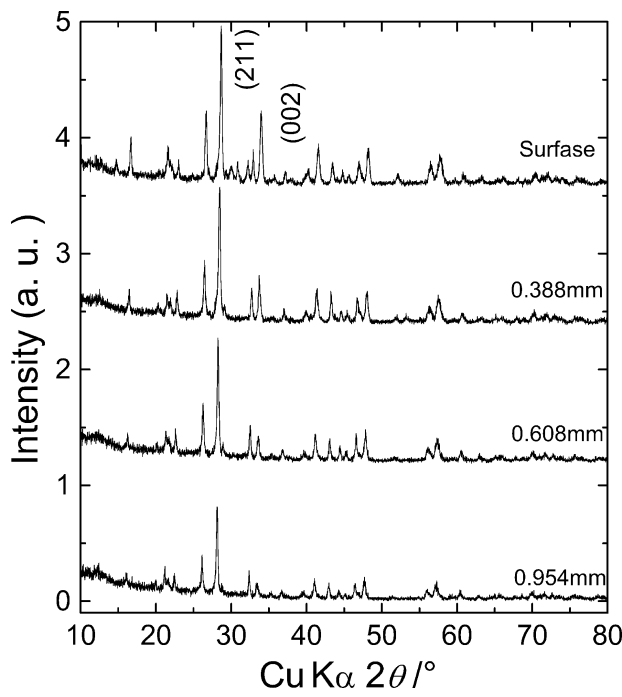

(b)

Fig. 1. XRD patterns of the surface and inside of the samples: (a-1) $x=9$, (a-2) $x=9\left(2 \theta=20^{\circ}\right.$ to $\left.30^{\circ}\right)$, and (b) $x=27$.

$$
O I=\frac{\left(I_{002}-0.2 I_{211}\right)}{\left(I_{002}+0.2 I_{211}\right)}
$$

The coefficient of " 0.2 " for $I_{211}$ indicates the diffraction peak intensity ratio between the (211) and (002) planes for the nonoriented crystal obtained from JCPDS data. ${ }^{24)}$

The changes of $O I$ in the depth direction of the samples are shown in Fig. 2. The sample of $x=9$, which was not the phaseseparated glass, has $c$-axis orientation at any depth. In contrast, no $c$-axis orientation is observed inside the phase-separated sample of $x=27$, because the same diffraction peak intensity ratios as those in the JCPDS data were observed at any depth, except at the surface. These results suggest the following. The surface crystallization occurred first for the non-phase-separated glass and the crystal growth proceeded inside the sample with $c$-axis orientation. In contrast, the phase separation in the glass promoted the crystallization inside the glass, which resulted in the apparent bulk crystallization. This apparent bulk crystallization was dominant for the phase-separated samples from the results of heat-treatment. This means that the boundary in the glass due to the phase separation could work as the heterogeneous nucleation points.

\subsection{Crystallization behavior under non-isothermal heat treatment}

The DTA curves were measured on the melt-quenched glasses in order to examine the effect of phase separation on the crystallization behavior under the non-isothermal heat treatment. As examples, the changes of the DTA curves with respect to the heating rate are shown in Figs. 3(a)-3(d) for samples of $x=9$ of different granular sizes and in Figs. 4(a)-4(d) for those of $x=27$. The crystallization temperature, $T_{\mathrm{p}}$, was evaluated from the peak temperature of the exothermic peak on the DTA curve. These temperatures are indicated by arrows on the curves in the figures. The data from the samples of granular size of $600-750 \mu \mathrm{m}$ were not used for the analysis, because the exothermic peaks of $x=27$ are so broad that the crystallization temperature was not determined precisely. In other samples having different com-

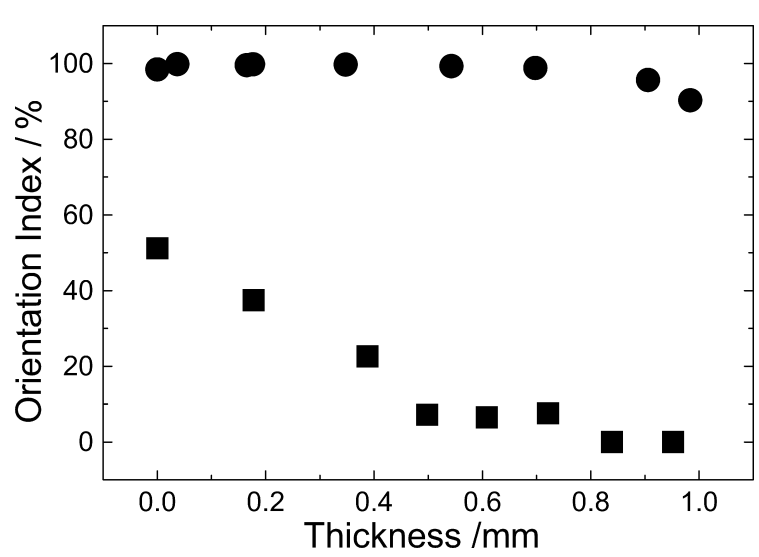

Fig. 2. Changes in the degree of the $c$-axis orientation index in the depth direction, $\bullet: x=9$ and $\mathbf{\square}: x=27$.

positions and granular sizes, $T_{\mathrm{p}}$ shifted higher with the increase of the heating rate. The exothermic peak became sharper as the granular size became smaller.

In the samples of different granular sizes, $\ln \left(\alpha / T_{\mathrm{p}}{ }^{2}\right)$ was plotted with respect to the inverse of the crystallization temperature, $1 / T_{\mathrm{p}}$ for all of the samples. In these plots, Eq. (2) at $n=1$ and $m=1$ was applied to all the samples. The results are shown in Figs. 5(a)-5(d). The relationships between the logarithm and the temperature were approximately linear in all of the samples having different compositions and granular sizes. Therefore, the apparent activation energy could be evaluated from the slope of the linear line, which was obtained by the least squares method. Figure 6 shows the changes of the evaluated activation energies with respect to the specific surface areas of the samples, which were calculated from the surface area and the volume of the corresponding sphere of the average particle size.

The activation energies of the crystal growth should basically be same for the respective samples, otherwise they are independent of their granular sizes. However, in the non-phase-separated samples of $x=9$ and 18, the apparent activation energy increased 
(a)

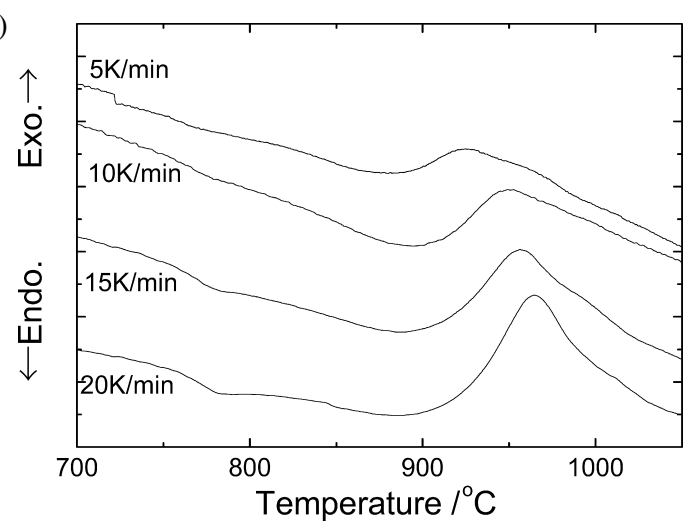

(b)

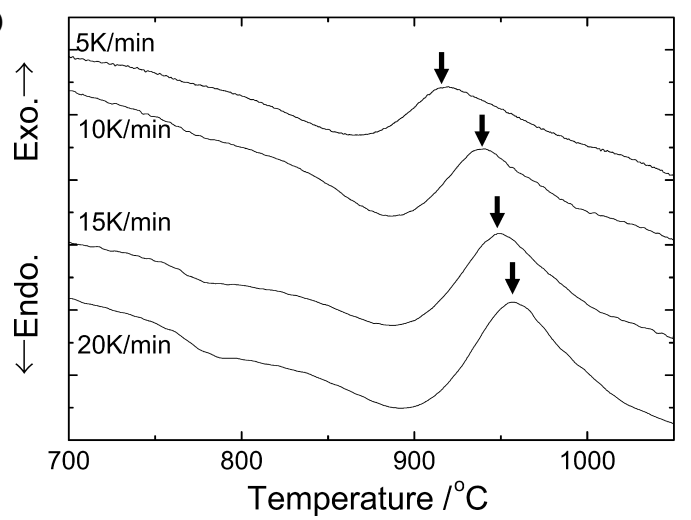

(c)

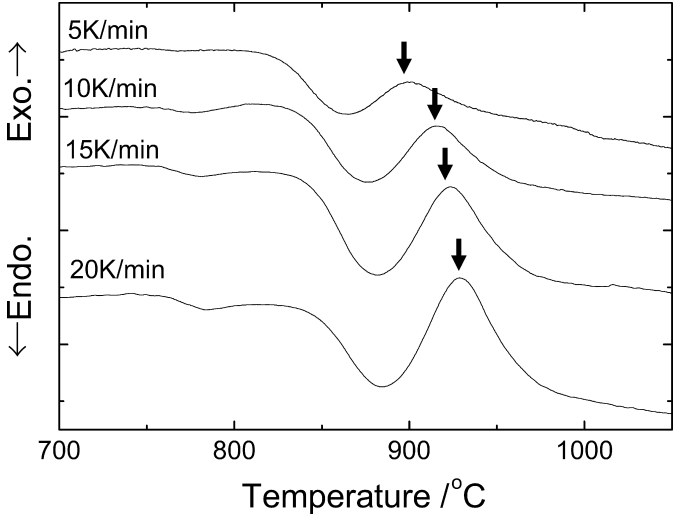

(d)

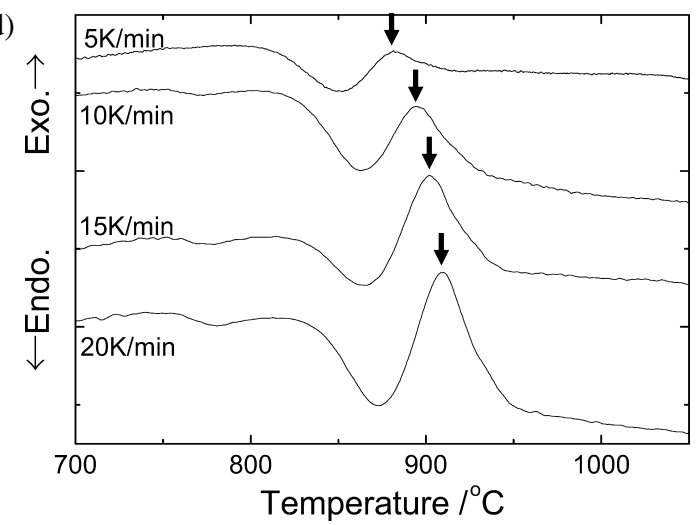

Fig. 3. Change in the DTA curves with heating rate for the different granular size of the samples of $x=9$ : (a) 600-750 $\mu \mathrm{m}$, (b) 300-600 $\mu \mathrm{m}$, (c) $75-150 \mu \mathrm{m}$, and (d) $32-45 \mu \mathrm{m}$.

(a)

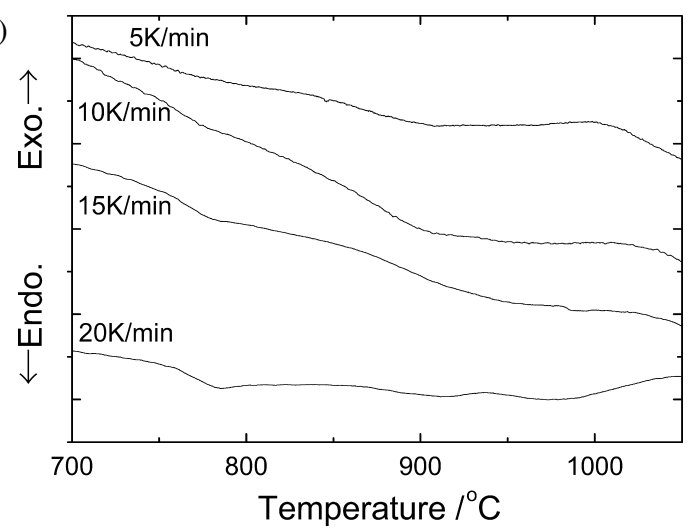

(b)

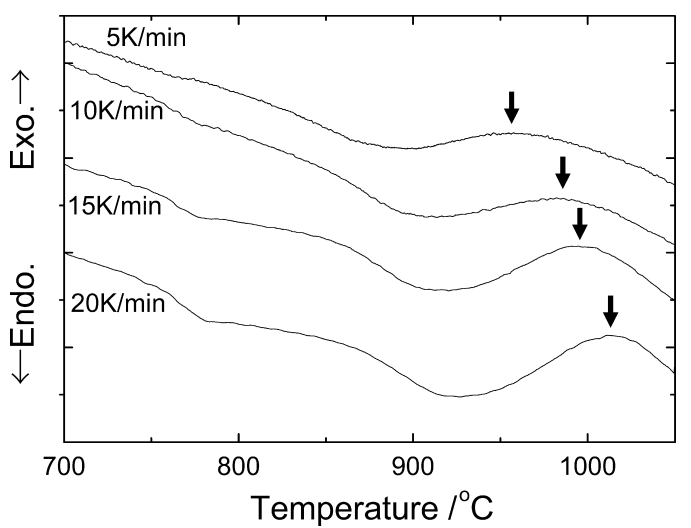

(c)

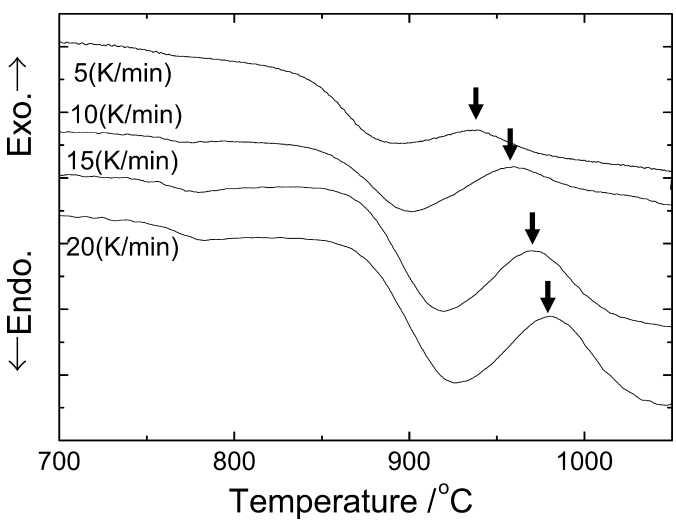

(d)

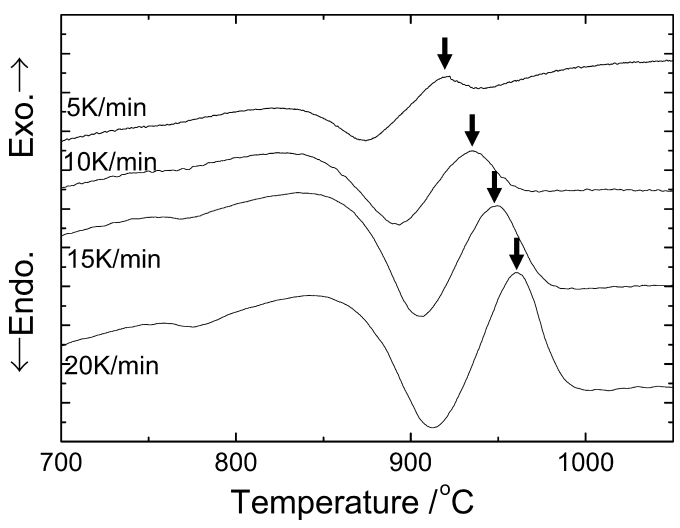

Fig. 4. Change in the DTA curves with heating rate for different granular sizes of the samples of $x=27$ : (a) 600-750 $\mu \mathrm{m}$, (b) 300-600 $\mu \mathrm{m}$, (c) $75-150 \mu \mathrm{m}$, and (d) $32-45 \mu \mathrm{m}$. 
(a)

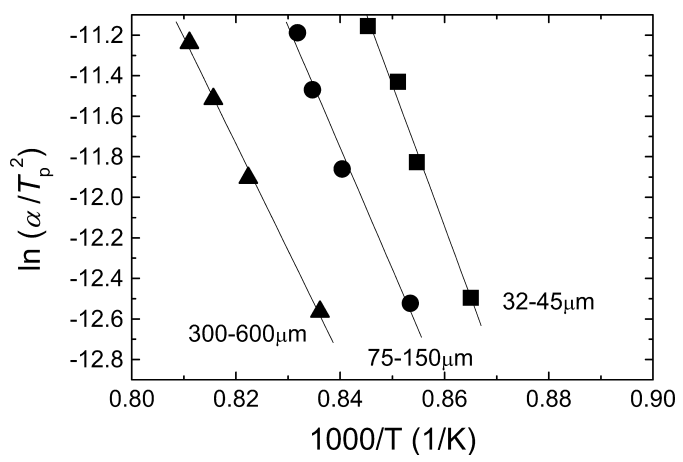

(b)

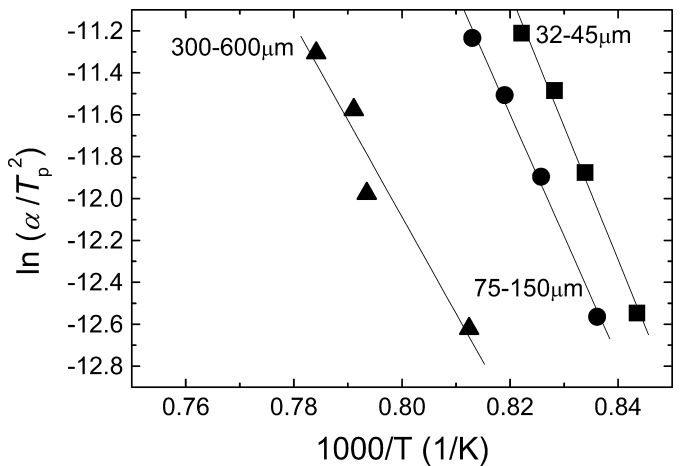

(c)

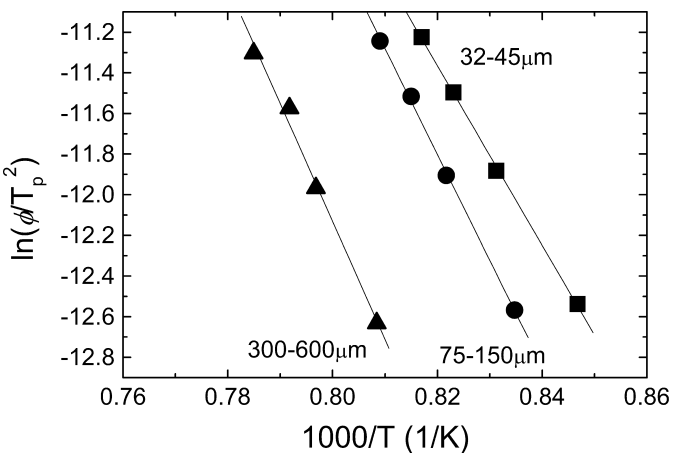

(d)

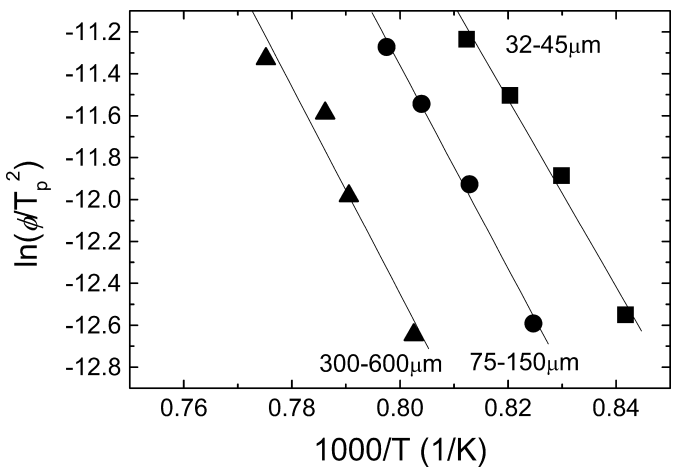

Fig. 5. Change in the modified Kissinger plot for samples with respect to the heating rate: (a) $x=9$, (b) $x=18$, (c) $x=21$, and (d) $x=27$.

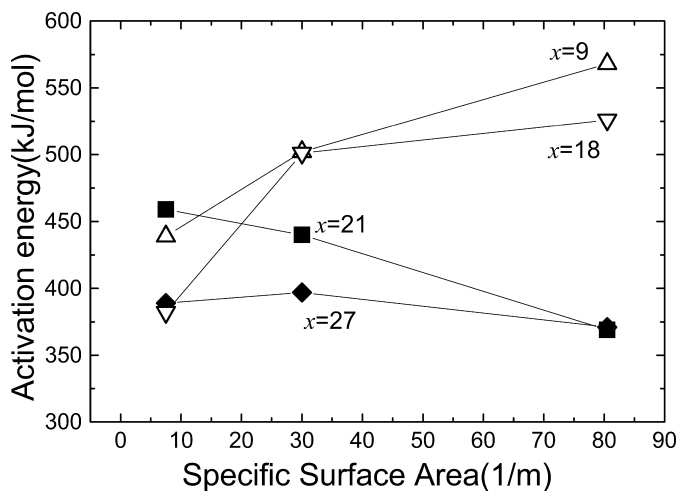

Fig. 6. Changes in the evaluated activation energies from the modified Kissinger plots with respect to the specific surface areas of the samples.

with the decrease of their granular sizes. In this case of surface crystallization, the rate of crystallization normally increases with the decrease of the granular size of the glass, ${ }^{25)}$ because the large surface area of the small particles enhances surface crystallization due to the increase in the heterogeneous nucleation points at their surfaces. In other words, the surface crystallization is dominant for the small particle sample and the bulk crystallization is dominant for the larger particle sample for the non-phaseseparated glasses. This result appears to differ from that of the $x=9$ glass-ceramics heat-treated at $1,000^{\circ} \mathrm{C}$ in the XRD measurement, which showed surface crystallization, because the isothermal heat-treated sample is not maintained at a homogeneous nucleation temperature.

The activation energies of the respective samples of $x=9$ were recalculated using Eq. (2) at $n=4$ and $m=3$. The recalculated activation energies of the samples are shown in Table 1, compared with those of the surface crystallization already calculated using Eq. (2) at $n=1$ and $m=1$. The activation energy of 602
Table 1. Activation Energies of the Crystallization of Fresnoite in the Sample of $x=9$ Evaluated from the Surface Crystallization Model ( $n=1$ and $m=1)$ and the Bulk Crystallization Model $(n=4$ and $m=3)$

\begin{tabular}{c|c|c|c}
\hline $\begin{array}{c}\text { Granular Size } \\
(\mu \mathrm{m})\end{array}$ & $\begin{array}{c}\text { Specific Surface Area } \\
(1 / \mathrm{m})\end{array}$ & $\begin{array}{c}\text { Surface crystallization } \\
E(\mathrm{~kJ} / \mathrm{mol})\end{array}$ & $\begin{array}{c}\text { Bulk crystallization } \\
E(\mathrm{~kJ} / \mathrm{mol})\end{array}$ \\
\hline $300-600$ & 7.5 & 436 & 602 \\
$75-150$ & 30 & 497 & 683 \\
$32-45$ & 80.5 & 579 & 791 \\
\hline
\end{tabular}

Table 2. Activation Energies of the Samples with $x=9,18,21$, and 27

\begin{tabular}{c|c|c}
\hline \multirow{2}{*}{$\begin{array}{c}\text { Concentration of } \\
\mathrm{SiO}_{2}, x(\text { mol\% })\end{array}$} & \multicolumn{2}{|c}{ Crystallization $E(\mathrm{~kJ} / \mathrm{mol})$} \\
\cline { 2 - 3 } & $\begin{array}{c}\text { Specific Surface } \\
\text { Area } 7.5(1 / \mathrm{m})\end{array}$ & $\begin{array}{c}\text { Specific Surface } \\
\text { Area } 80(1 / \mathrm{m})\end{array}$ \\
\hline 9 & 602 & $579^{*}$ \\
18 & 531 & $526^{*}$ \\
21 & 632 & 512 \\
27 & 515 & 515 \\
\hline
\end{tabular}

*; the surface crystallization $(n=1$ and $m=1)$

$\mathrm{kJ} / \mathrm{mol}$ for the bulk crystallization of the large particle size (300$600 \mu \mathrm{m}$ ) closely approaches that of $579 \mathrm{~kJ} / \mathrm{mol}$ for the surface crystallization of the small particle size (32-45 $\mu \mathrm{m})$. According to the same consideration on the effect of the particle size on the activation energy of the sample of $x=9$, the activation energy of the sample of $x=18$ with large particle size should be recalculated using Eq. (2) at $n=4$ and $m=3$. In contrast, Eq. (2) at $n=4$ and $m=3$ should be applied to the phase-separated glasses because they showed bulk crystallization based on the results of the isothermal heat treatment. These recalculated activation energies are summarized in Table 2. 
The activation energy for the phase-separated sample of $x=27$ was approximately constant or independent of the granular size of the samples. In a phase-separated glass, the interface between two glassy phases, which is much wider than the surface of the glass, can predominantly act as a heterogeneous nucleation site. Therefore, as a result of the independence of the specific area of the interface, the activation energy does not depend on its particle size.

However, in the sample of $x=21$, the activation energy increased with the increase of the granular size. In order to explain this change in terms of the above theory, the nucleation parameter $a$ should be negative. This negative $a$ indicates that the number of nuclei in the glass decreased during a heat treatment. ${ }^{26)}$ Therefore, in the sample of $x=21$, the phase separation grew during the heat treatment in the DTA measurement and caused a decrease in the interface between the two glass phases or a decrease in the number of heterogeneous nucleation points. Therefore, based on the results for the fine granular sample, the activation energy in this composition is expected to be $510-530$ $\mathrm{kJ} / \mathrm{mol}$.

These results shown in Table 2 indicate that the activation energy of the crystallization of fresnoite in this composition area is $500-600 \mathrm{~kJ} / \mathrm{mol}$. The activation energies of the $\mathrm{BaO}-\mathrm{TiO}_{2}$ rich glasses compared with a fresnoite composition in this ternary system have been reported to be around $300 \mathrm{~kJ} / \mathrm{mol}$ in the range of $1 / 2(100-y) \mathrm{BaO}-1 / 2(100-y) \mathrm{TiO}_{2}-y \mathrm{SiO}_{2}$ of $\mathrm{y}=20-40(\mathrm{~mol} \%),{ }^{20)}$ and the glass having a composition similar to that of the sample of $x=9$ has been reported to be $518 \mathrm{~kJ} / \mathrm{mol}$ in the composition of $33.33 \mathrm{BaO}-16.66 \mathrm{TiO}_{2}-50 \mathrm{SiO}_{2}(\mathrm{~mol} \%){ }^{19)}$ This value is very close to $579 \mathrm{~kJ} / \mathrm{mol}$ of $x=9$. Based on these comparisons, in this glass system, the activation energies of the crystallization of fresnoite are different between glasses of $\mathrm{BaO}-\mathrm{TiO}_{2}$ rich and $\mathrm{SiO}_{2}$ rich compositions. In our glass samples, of which compositions are $\mathrm{SiO}_{2}$ rich, the activation energies are independent of the initial glass composition and the existence of the phase separation, although the crystallization behavior is largely influenced by the phase separation.

In order to confirm the above discussions on the effect of the phase separation, the morphologies of the phase separation and the crystallization were observed by SEM on the as-quenched samples of $x=9$ and $x=27$ and on those samples that were heat treated at $1,200^{\circ} \mathrm{C}$ for 15 minutes. The SEM images of the surfaces and the cross-sections of these samples are shown in Figs. 7(a-1) and 7(a-2) for $x=9$ and Figs. 7(b-1) and 7(b-2) for $x=$ 27. The as-quenched sample of $x=9$ showed no phase separation texture in the image (Fig. 7(a-1)). In contrast, the sample of $x=$ 27 showed obvious phase separation texture of several hundreds of nanometers, where the dark discrete areas correspond to $\mathrm{SiO}_{2}-$ rich phase, and the bright matrix is $\mathrm{BaO}-\mathrm{TiO}_{2}$-rich phase. The as-quenched sample of $x=21$ was transparent and appeared as homogeneous glass, but a phase separation texture similar to that of $x=27$ was observed by SEM at the portion of the airquenched (slowly cooled) surface. This indicates that the phase separation occurred very finely at nanometer scale because the glass composition of $x=21$ is located just inside the immiscibility region. After the heat treatment, in the heat-treated sample of $x=9$, the crystallization proceeded to completion, and the crystal grains grew large near the surface. However, in the heat-treated sample of $x=27$, the crystallization at the surface was not conspicuous, and the inner $\mathrm{BaO}-\mathrm{TiO}_{2}$-rich phase crystallized. The size of the crystallized phase was approximately $1 \mu \mathrm{m}$ and was related to that of a microstructure of several hundred nanometers in the melt-quenched glass. These results suggest that the surface
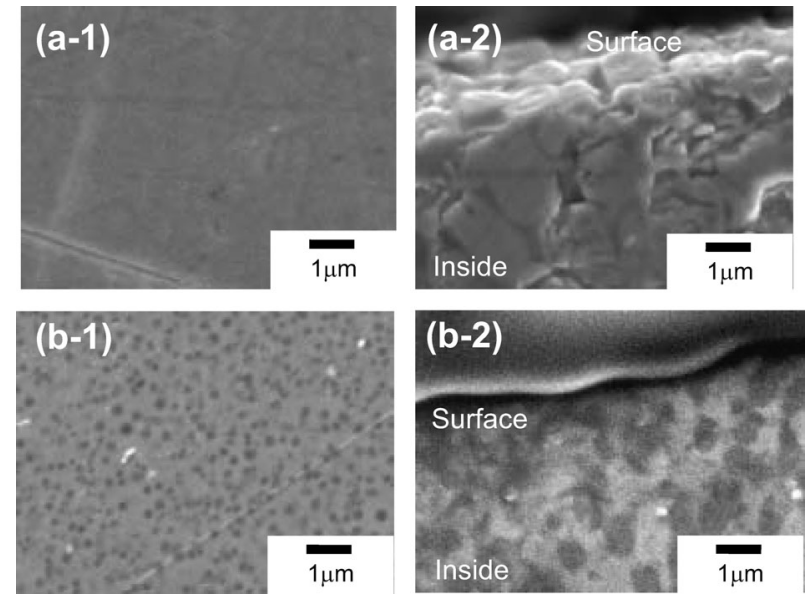

Fig. 7. SEM images of the samples: (a-1) and (b-1) are the surfaces of $x=9$ and 27 before crystallization, and (a-2) and (b-2) are the cross sections of $x=9$ and 27 after crystallization.

crystallization and the subsequent crystal growth proceeded in the non-phase-separated glass and that apparent bulk crystallization occurred in $\mathrm{BaO}-\mathrm{TiO}_{2}$-rich phase from the boundary of the phase separation as base points of nucleation.

Based on the above results and discussions, the phase separation was found to significantly affect the behavior of the crystallization. Thus, we propose the following crystallization model by heat treatment in the $\mathrm{SiO}_{2}$-rich compositions in this ternary system. The evaluated activation energies of the fresnoite growth in the sample glasses were approximately same, but the nucleation processes were very different. In the non-phase-separated glasses, the surface nucleation and subsequent surface crystallization of fresnoite occurs first, followed by inner crystallization with $c$-axis-oriented growth. In contrast, in the phase-separated glasses, the crystallization starts at the boundary of two glass phases inside the melt-quenched glass and the crystals, namely fresnoite, grow in the $\mathrm{BaO}-\mathrm{TiO}_{2}$-rich phases.

\section{Conclusions}

It is necessary to control the precipitating condition of fresnoite in the glass matrix in order to prepare high photo-emitted phosphor glass ceramics in the $\mathrm{BaO}-\mathrm{TiO}_{2}-\mathrm{SiO}_{2}$ system. In the present study, we investigated the effect of the phase separation that formed inside the glass on the crystallization behavior. We found differences in the crystallization mechanisms, which were affected by the existence of the phase separation rather than the initial composition. The apparent bulk crystallization occurred in the phase-separated glasses because the boundary of two glass phases acted as heterogeneous nucleation points. This apparent bulk crystallization has the potential to synthesize phosphor composite, which consists of very fine phosphor particles uniformly dispersed in a transparent medium for excitation and emission lights. This apparent bulk crystallization glass causes multiple light scattering and results in high photoluminescence intensity. The phase separation of the glass contributed to a welldesigned and controlled crystallization process for highperformance phosphor materials.

\section{References}

1) N. M. Lawandy and R. M. Balachandran, Nature, 368, 436437 (1994).

2) Z. Yao, Y. Ding, T. Nanba and Y. Miura, J. Ceram. Soc. 
Japan, 106, 1043-1047 (1998).

3) N. Kiso and A. Yasumori in Proc. XX ICG, O-07-070 (2004).

4) T. Ohgaki A. Higashida, K. Soga and A. Yasumori, J. Electro. Soc., 154, J163-J166 (2007).

5) T. Ohgaki, Y. Nagumo, K. Soga and A. Yasumori, J. Ceram. Soc. Japan, 115, 201-204 (2007).

6) H. Hijiya, T. Kishi and A. Yasumori, J. Ceram. Soc. Japan, 116, 1255-1259 (2008).

7) M. Avrami, J. Chem. Phys., 7, 1103-1112 (1939).

8) M. Avrami, J. Chem. Phys., 8, 212-224 (1940).

9) M. Avrami, J. Chem. Phys., 9, 177-184 (1941).

10) K. Matusita and S. Sakka, J. Non-Cryst. Solids, 38\&39, 741746 (1980)

11) K. Matusita, T. Komatsu and R. Yokota, J. Mater. Sci., 19, 291-296 (1984).

12) C. S. Ray and D. E. Day, J. Am. Ceram. Soc., 67, 806-809 (1984).

13) T. Takei, Y. Kameshima, A. Yasumori and K. Okada, J. Am. Ceram. Soc., 82, 2876-280 (1999).

14) K. Matusita, T. Maki and M. Tashiro, Phys. Chem. Glasses, 15, 106-108 (1974)
15) V. Komppa, Phys. Chem. Glasses, 20, 130-134 (1979).

16) Y. Takahashi, Y. Benino, T. Fujiwara and T. Komatsu, J. Appl. Phys., 95[7], 3503-3508 (2004).

17) Y. Takahashi, K. Kitamura, S. Inoue, Y. Benino, T. Fujiwara and T. Komatsu, J. Ceram. Soc. Japan, 113, 419-423 (2005).

18) A. A. Cabral, V. M. Fokin, E. D. Zanotto and C. R. Chinaglia, J. Non-Cryst. Solids, 330, 174-186 (2003).

19) Y. Ochi, T. Moguro and K. Kakogawa, J. Eur. Ceram. Soc., 26, 627-630 (2006).

20) C. S. Ray and D. E. Day, L. Non-Cryst. Solids, 81, 173-183 (1986).

21) H. E. Kissinger, J. Res. Natl Bur. Stand., 57, 217-221 (1956).

22) S. Ranganthan and M. Von Heimendahk, J. Mater. Sci., 16, 2401-2404 (1981).

23) K. Matusita, K. Miura and T. Komatsu, Thermochimica Acta, 88, 283-288 (1985).

24) H. J. Borchart, J. Inorg. Nucl. Chem. 12, 252-254 (1960).

25) C. S. Ray, Q. Yang, W.-H. Huang, D. E. Day, J. Am. Ceram. Soc., 79, 3155-3160 (1996).

26) K. Matusita, J. Mater. Sci., 10, 961-966 (1975). 